\title{
Maturational Changes in Myocardial Contractile State of Newborn Lambs
}

\author{
THOMAS A. RIEMENSCHNEIDER, ${ }^{(3+)}$ ROBERT A. BRENNER, and DEAN T. MASON \\ Sections of Cardiovascular Pediatrics and Cardiovascular Medicine, Departments of Pediatrics, Medicine, and \\ Physiology, University of California, Davis, School of Medicine, Davis, California, and University of California Davis \\ Medical Center, Sacramento, California, USA
}

\section{Summary}

There have been no investigations of chronologic changes in postnatal contractile state of both left and right ventricles of the newborn. Thus, we determined isovolumetric indices of contractility in 32 acutely instrumented newborn lambs (1 day to 12 wk; three exteriorized near term fetuses, and four adult sheep. These studies demonstrated a marked increase in inotropic properties of both ventricles which was especially pronounced during the first 3 days of extrauterine life (group 1, left ventricle $V_{\max } 3.2 \pm 0.27$ and $V_{\text {CE10 }} 3.2 \pm 0.28 \mathrm{ML}$ (muscle lengths)/sec; right ventricle $V_{\max } 2.1 \pm 0.2$ and $V_{\text {CE10 }} 2.2 \pm 0.13 \mathrm{ML} / \mathrm{sec}$ ); and was associated with elevated cardiac output $(428 \pm 52 \mathrm{cc} / \mathrm{kg} / \mathrm{min})$, largely resulting from an elevated stroke volume $(2.1 \pm 0.31 \mathrm{cc} / \mathrm{kg})$. During subsequent postnatal maturation, contractility indices of both ventricles gradually declined to values intermediate between newborn and adult I(group IV, 22 to 84 days) - left ventricle $V_{\max }$ $1.78 \pm 0.13$ and $V_{C E 10} 1.79 \pm 0.15 \mathrm{ML} / \mathrm{sec}$; right ventricle $V_{\max }$ $1.48 \pm 0.07$ and $V_{\text {CE10 }} 1.31 \pm 0.3 \mathrm{ML} / \mathrm{sec}$; associated with a corresponding decline in cardiac output (group IV, $136 \pm 38 \mathrm{cc}$ / $\mathrm{kg} / \mathrm{min}$ ), related in large measure to a decline in stroke volume $(0.76 \pm 0.13 \mathrm{cc} / \mathrm{kg})$. Simulation of birth in exteriorized fetuses was associated with a sudden increase in contractile indices for both left $\left(V_{\max } 2.1 \pm .2 \rightarrow 3.0 \pm .3\right.$ and $V_{\text {CE10 }} 2.1 \pm 0.2 \rightarrow 3.1 \pm 0.3$ $\mathrm{ML} / \mathrm{sec})$ and right $\left(\mathrm{V}_{\max } 2.0 \pm 0.2 \rightarrow 2.5 \pm 0.2\right.$ and $\mathrm{V}_{\text {CE10 }} 1.9 \pm$ $0.1 \rightarrow 2.5 \pm 0.2 \mathrm{ML} / \mathrm{sec}$ ) ventricles. We conclude that there is a postnatal elevation of ventricular contractile state which contributes to successful postnatal adaptation of the newborn cardiovascular system.

\section{Speculation}

The increased metabolic demands associated with adaptation to extrauterine life are met by an increased cardiac output in the newborn. The necessary cardiac output may be accomplished in part through an elevation of myocardial contractile state, induced by postnatal increases in circulating hormones.

There have been few chronologic studies of the hemodynamic adaptations of the intact newborn heart to extrauterine life $(1,17)$ The newborn heart has been shown to be structurally and functionally immature $(7,13,26)$. Despite this immaturity, hemodynamic alterations associated with the birth process result in a sudden persisting elevation in cardiac output in the first week of postnatal life $(1,17)$. Thus, the immature newborn heart must abruptly adapt to meet the increased hemodynamic demands placed upon it following birth. One mechanism by which this adaptation may be accomplished is through an increase in ventricular contractility. The purpose of this investigation was to examine maturational changes in both left and right ventricular contractile state from birth through the first 3 months of extrauterine life and to relate these alterations to postnatal changes in cardiac output. Our findings document an important myocardial adaptation of the newborn cardiovascular system to meet the increased metabolic requirements during early extrauterine life.

\section{MATERIALS AND METHODS}

Thirty-two healthy lambs (ages $2 \mathrm{hr}$ to $12 \mathrm{wk}$ ) were anesthetized with 40 to $60 \mathrm{~mm} / \mathrm{kg}$ of alpha chloralose IV, intubated, and placed on a Harvard respirator. A stiff polyethylene catheter was introduced into the femoral artery and advanced into the descending thoracic aorta. The catheter was connected to a Statham P-23Db transducer (precalibrated against a mercury manometer) for continuous measurement of aortic pressure and was also utilized for sequential determinations of arterial blood gases.

A left thoracotomy was performed with removal of the fourth, fifth, and sixth ribs. The pericardial sac was opened from the apex of the heart diagonally to the great vessels, which were dissected free of surrounding fat and connective tissue. The ductus arteriosus was identified, dissected free, and ligated in each animal. Highfidelity Konigsberg P-13 microtransducers were introduced through stab wounds into the apices of both the right and left ventricles and stabilized with purse-string sutures. A stiff fluidfilled polyethylene catheter was introduced into the proximal main pulmonary artery and connected to a precalibrated P-23Db Statham transducer. The Konigsberg microtransducers were calibrated in vivo by matching their output signal to the pressure tracing obtained by the corresponding fluid-filled catheter. Appropriate sized, precalibrated Biotronex flow probes were placed around the base of each great vessel. Electrocardiographic leads were placed on the torso.

Meticulous care was taken with each step in the protocol to preserve blood flow and ventilatory function, avoid blood loss, and maintain tissue oxygenation. The application of carefully developed surgical techniques to instrument the animals resulted in only minimal blood losses which were immediately replaced cc for cc with saline warmed to body temperature. Throughout the procedure, the lungs were frequently bathed in warmed saline and re-expanded periodically to ensure adequate ventilation. Arterial blood gases were monitored every 15 to $30 \mathrm{~min}$ and remained within the following limits during the experimental protocol: $\mathrm{pH}$, 7.35 to $7.45 ; \mathrm{PO}_{2}, 60$ to $90 \mathrm{~mm} \mathrm{Hg}$; and $\mathrm{PCO}_{2}, 25$ to $40 \mathrm{~mm} \mathrm{Hg}$.

To evaluate the possible effects of acute alterations in hemodynamic parameters on indices of contractile state, we performed acute volume and pressure loading as well as inotropic stimulation of left and right ventricles in two lambs of each age group (Fig. 1). End-diastolic pressures and volumes were increased by infusion of warmed saline $(30 \mathrm{cc} / \mathrm{kg} / 2 \mathrm{~min})$ into the left or right atrium. Aortic and pulmonary artery pressures were increased by progressively snaring the distal ascending aorta or main pulmonary artery. Responsiveness of contractile indices to change in inotropic state was evaluated by administering isoproterenol $(0.05 \mu / \mathrm{kg} / \mathrm{min} \mathrm{IV})$.

Four adult sheep (ages 1 to 3 years) were anesthetized with 80 $\mathrm{mg} / \mathrm{kg}$ IV of alpha chloralose, intubated, and placed on a Harvard respirator. We then performed thoracotomy, pericardiotomy, and placement of fluid-filled catheters into the great vessels, and Konigsberg microtransducers in both left and right ventricles. Left and right ventricular pressures and their first derivatives, as well as pulmonary artery and aortic pressures, together with the electrocardiographic signal were recorded under resting conditions, permitting the determination of isovolumic indices. 
EFFECT OF HEMOOYNAMIC VARIABLES ON CONTRACTILE INDICES
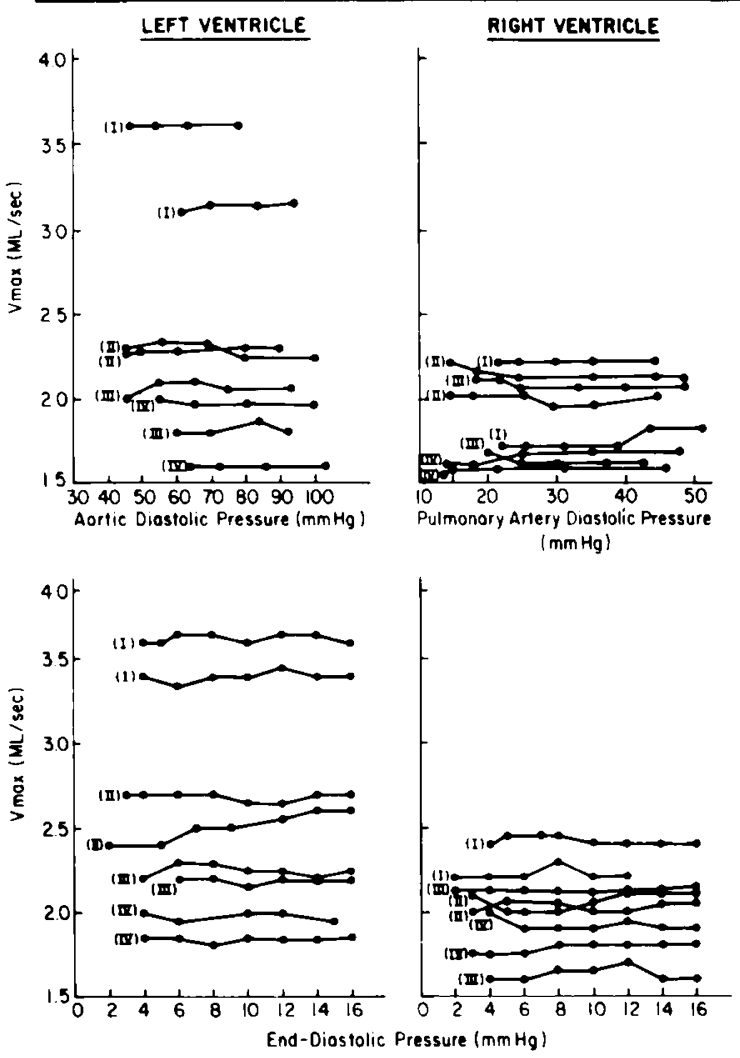

INOTROPIC STIMULATION
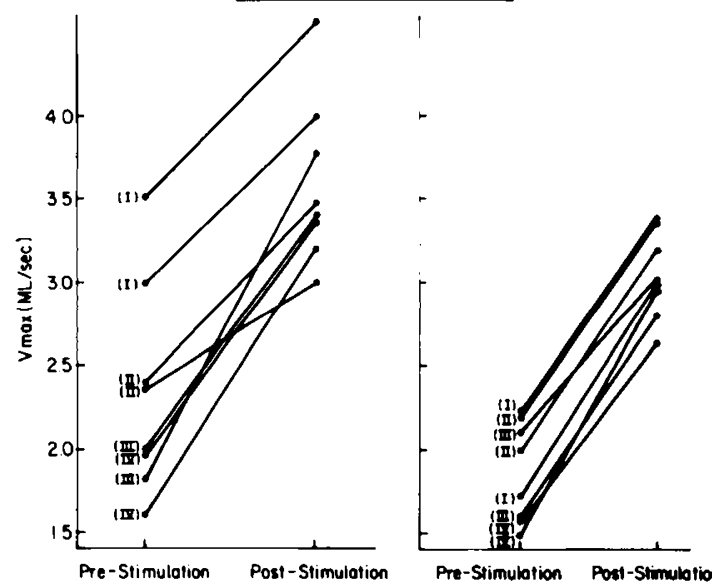

Fig. 1. Effect of hemodynamic variables on contractile indices.

Top, effect of acutely increasing aortic diastolic pressure on left ventricular $\mathrm{V}_{\max }(l e f t)$ and acutely increasing pulmonary artery diastolic pressure on right ventricular $\mathrm{V}_{\max }$ (right). Lack of change of left and right ventricular $V_{\max }$ in response to acute increases in afterload for two newborn lambs of each age group (I to IV).

Middle, effect of acutely increasing end-diastolic pressure on left (left) and right (right) ventricular $\mathrm{V}_{\max }$. Lack of change of left and right ventricular $\mathrm{V}_{\max }$ in response to acute responses in preload for two newborn lambs of each age group (I to IV).

Bottom, effect of acute inotropic stimulation on $\mathrm{V}_{\text {max }}$. Marked increase in both left (left) and right (right) ventricular $\mathrm{V}_{\max }$ in response to infusion of $0.05 \mu \mathrm{g} / \mathrm{kg}$ of isoproterenol IV. Calculated values for $V_{(E, 1)}$ showed similar patterns of response to changes in loading conditions and inotropic state. $\mathrm{ML} / \mathrm{sec}$, muscle lengths/sec; $\mathrm{mm} \mathrm{Hg}, \mathrm{mm}$ of mercury.

In a separate series of experiments, three near-term ewes were anesthetized with $80 \mathrm{mg} / \mathrm{kg}$ of IV of alpha chloralose. After infiltration with $1 \%$ lidocaine local anesthesia, a midline lower abdominal incision was made, the uterus was marsupialized to the abdominal incision, and the fetus was exteriorized onto an adjacent heated tray. The umbilical cord was suspended in a constant temperature waterbath containing saline at body temperature.

Each fetus was immediately dried and placed on its side, and both mouth and nose were covered with a saline-filled rubber glove to prevent respiration. Rectal temperature was monitored and maintained within the physiologic range $\left(38\right.$ to $\left.40^{\circ} \mathrm{C}\right)$, by means of a heating pad. A left thoracotomy was rapidly performed with removal of the fourth and fifth ribs. The pericardial sac was opened, and Konigsberg microtransducers were placed in both ventricles; fluid-filled catheters were positioned in the aorta and pulmonary artery, and peripheral electrocardiographic leads were attached. Left and right ventricular pressures and derivatives, aortic and pulmonary artery pressures, the electrocardiographic signal, arterial blood gases, and rectal temperature were monitored for $15 \mathrm{~min}$ after instrumentation to determine stability of the preparation. The saline-filled glove was then removed, the trachea was intubated and suctioned, and the lamb placed on a respirator. Simultaneously the umbilical cord was clamped and hemodynamic recordings were made immediately and at frequent intervals for the next $60 \mathrm{~min}$.

In all experiments on fetuses, newborn lambs, and adult sheep, pressure signals from Konigsberg microtransducers were processed by Honeywell Accudata No. 143 pressure amplifiers and by Honeywell No. 135 differentiators to provide continuous determination of instanteous $\mathrm{dp} / \mathrm{dt}$. Aortic and pulmonary artery pressure signals from Statham $23 \mathrm{db}$ transducers were processed by Honeywell No. 113 pressure amplifiers. Flow signals in newborn lambs were processed by Biotronex No. 613 flow meters, and Biotronex No. 620 integrators to provide beat-by-beat determination of stroke volume.

Hemodynamic variables were visualized on an eight-channel Honeywell oscilloscope and recorded on an 18-channel Honeywell No. 1912 Visicorder at a paper speed of $20 \mathrm{~cm} / \mathrm{sec}$. For each ventricle, we recorded ventricular and arterial pressures, the first derivatives of ventricular pressure, phasic flow, and integral of flow (stroke volume), and the peripheral EKG signal. From a stable noise-free portion of the tracing, we analyzed six consecutive beats measuring: heart rate, aortic and pulmonary artery pressures, and ventricular end-diastolic pressures.

In addition, we measured instantaneous $\mathrm{dp} / \mathrm{dt}$ and corresponding ventricular pressure every $5 \mathrm{msec}$ throughout isovolumic systole for both left and right ventricles.

From these measurements, we determined two isovolumetric indices of contractile state. Because the exact model for cardiac contraction is not precisely known, we determined $V_{\max }$ an index based upon a two-element muscle model, and $\mathrm{V}_{\mathrm{CE} 10}$, an index which is based upon a three-element model. The maximal velocity of muscle shortening at zero load $\left(\mathrm{V}_{\max }\right)$ was determined from pressure-velocity curves obtained by comparing total isovolumic pressure (IP) to calculated instantaneous velocity of contractile element shortening $\left(\mathrm{V}_{\mathrm{CE}}\right)$ every $5 \mathrm{msec}$ during isovolumic systole. The velocity of contractile element shortening was calculated from instantaneous $\mathrm{dp} / \mathrm{dt}$ and its corresponding total isovolumic pressure according to the formula $\mathrm{V}_{\mathrm{CE}}=(\mathrm{dp} / \mathrm{dt}) / \mathrm{IP} \cdot(\mathrm{K}+\mathrm{c})$ with $\mathrm{K}$ and $\mathrm{c}$ representing constants of series elasticity. Because $\mathrm{c}$ is exceedingly small, it was eliminated from the calculations, as others have done by custom (20). Further, because $\mathrm{K}$ has not been determined for newborn lamb myocardium, we utilized a value of $32 /$ muscle length, which had been previously determined in adult animals at normal body temperature (31). Thus, instantaneous $V_{C E}$ values were actually calculated from the formula $V_{C E}=(d p /$ $\mathrm{dt}) /(\mathrm{IP} \cdot 32)$ and plotted against total isovolumic pressure. Extrapolation of the descending limb of the resulting pressure velocity curve to zero pressure permitted us to determine the inotropic index of unloaded contractile element shortening $\left(\mathrm{V}_{\max }\right)$. By utilizing a straight line to join the points on the descending limb, we minimized errors inherent in extrapolation to a distant point (20).

The second index of contractile state, $V_{C_{E 11}}$, accounts for a parallel elastic element by substituting ventricular developed pressure (DP) (DP = total isovolumic pressure minus end-diastolic 
pressure) for total pressure in the calculation of velocity of contractile element shortening, $V_{C E}=(d p / d t) /(D P \cdot 32)(29,31)$. The resulting developed pressure-velocity curve assumes a parabolic configuration, the upper portion approaching zero pressure asymptotically. For this reason, the index of contractile state, $V_{\text {Cki1 }}$, has, by convention, been taken as the point at which this curve is related to $10 \mathrm{~mm} \mathrm{Hg}$. Thus, the determination of $V_{C E 11}$ requires no extrapolation and also allows determination of a descending limb of the pressure-velocity curve in ventricles with very low isovolumic pressure (29).

To facilitate data analysis, eight newborn lambs were included in each of four groups: Gp I ( 1 to 3 days), Gp II ( 4 to 9 days), Gp III ( 10 to 21 days), and Gp IV ( 22 to 84 days). Data from the four adult sheep ( 1 to 3 years) were considered as a group. Finally. data from three exteriorized fetuses were examined separately. The Student $t$ test for unpaired data was utilized to compare corresponding results from newborns (Gps I to IV). A $P$ value of $\leq 0.05$ was considered statistically significant.

\section{RESULTS}

Body weights of the newborn lambs increased progressively with age: Gp I, $3.7 \pm 0.35 \mathrm{~kg}$; Gp II, $5.2 \pm 1.1 \mathrm{~kg}$; Gp III, $7.25 \pm$ $1.8 \mathrm{~kg}$; and group IV, $14.1 \pm 3.3 \mathrm{~kg}$. Stability of the experimental preparations was documented by monitoring of rectal temperatures $\left(\mathrm{Gp} \mathrm{I}, 39 \pm 1.5^{\circ} \mathrm{C}, \mathrm{Gp} \mathrm{II}, 39 \pm 1.2^{\circ} \mathrm{C}\right.$; Gp III, $39 \pm 1.2^{\circ} \mathrm{C}$; and $\mathrm{Gp} \mathrm{IV}, 39 \pm 0.8^{\circ} \mathrm{C}$ ) and arterial blood gases ( $\mathrm{Gp} \mathrm{I}, \mathrm{pH}=7.39$ $\pm 0.1, \mathrm{PO}_{2}=70 \pm 12 \mathrm{~mm} \mathrm{Hg}, \mathrm{PcO}_{2}=28 \pm 3.6 \mathrm{~mm} \mathrm{Hg} ; \mathrm{Gp} \mathrm{Il}, \mathrm{pH}$ $=7.36 \pm 0.12, \mathrm{PO}_{2}=74 \pm 9 \mathrm{~mm} \mathrm{Hg}, \mathrm{PCO}_{2}=30 \pm 4.0 \mathrm{~mm} \mathrm{Hg} ; \mathrm{Gp}$ III, $\mathrm{pH}=7.40, \mathrm{PO}_{2}=86 \pm 17 \mathrm{~mm} \mathrm{Hg}, \mathrm{PCO}_{2}=30 \pm 5.0 \mathrm{~mm} \mathrm{Hg}$; $\mathrm{Gp} \mathrm{IV}, \mathrm{pH}=7.39 \pm 0.1, \mathrm{Po}_{2}=83 \pm 12 \mathrm{~mm} \mathrm{Hg}, \mathrm{PcO}_{2}=35 \pm 4.0$ $\mathrm{mm} \mathrm{Hg}$ ).

Mean values for hemodynamic parameters of each of the older age groups (II, III, and IV) were compared with those of the youngest lambs ( $\mathrm{Gp} \mathrm{I}$, ages 1 to 3 days) (Table I). Heart rate decreased progressively with increasing age, although a statistically significant decrease was achieved only in the oldest lambs (Gp IV). Mean aortic pressure was similar in younger lambs (Gps I to III) but significantly higher in older lambs (Gp IV). In contrast, mean pulmonary artery pressure was progressively lower in Gps II, III, and IV as compared with the newborn values of Gp I. End-diastolic pressures of left and right ventricles did not change significantly with maturation. Peak $\mathrm{dp} / \mathrm{dt}$ was highest at birth for both left and right ventricles and diminished significantly for left (Gps II, III, and IV) and right ventricles (Gps III and IV) in older lambs. Although absolute left ventricular stroke volume increased significantly with maturation (Gps III and IV), both stroke volume $/ \mathrm{kg}$ and cardiac output $/ \mathrm{kg}$ were elevated in the newborn (Gp I) and significantly lower in older lambs (Gps II, III, and IV).

Calculated isovolumetric indices of contractile state $\left(\mathrm{V}_{\max }\right.$ and $\mathrm{V}_{\mathrm{CE} \text { in }}$ ) were elevated in the first 3 days of postnatal life for both left and right ventricles (Table 1). Similar temporal patterns of change for both ventricles were demonstrated with maturation. When compared with values obtained in the immediate newborn period $(\mathrm{Gp} \mathrm{I})$, there was a progressive decline in calculated indices for both left and right ventricles of older lambs (Gps II, III, and IV), which was statistically significant. These changes in contractile indices were paralleled by a maturational decline in both stroke volume $(\mathrm{cc} / \mathrm{kg})$ and cardiac output $(\mathrm{cc} / \mathrm{kg} / \mathrm{min})$ (Table I).

Compared to the adult sheep, newborn lambs (Gps I to IV) demonstrated faster heart rates, lower aortic and higher pulmonary artery pressures, higher left and right ventricular peak $\mathrm{dp} / \mathrm{dt}$. and similar end-diastolic pressures (Table 1). Calculated indices of contractile state were greater for both left and right ventricles of all newborn lambs compared with corresponding adult values

Acute elevations in aortic pressure did not change left or right ventricular $\mathrm{V}_{\max }$ or $\mathrm{V}_{\mathrm{CE} 10}$ in two lambs from each age group (Fig. 1). When ventricular end-diastolic pressure and volume were acutely increased by infusion of warmed saline, there was no change in either index of contractile state for either ventricle Within the limits defined by these acute interventions, contractile indices were not altered by acute elevations in preload or afterload over a range which exceeded the experimental conditions of our protocol. When inotropic state was stimulated by infusion of isoproterenol, left and right ventricular $\mathrm{V}_{\max }$ and $\mathrm{V}_{\mathrm{CE} 10}$ increased immediately in all lambs.

After instrumentation of the exteriorized fetuses, no significant changes in hemodynamic parameters or indices of contractile state were noted on two consecutive determinations separated by a 15 min interval (Table 2). After cord clamping and ventilation, heart rate increased significantly, but returned to initial values by 40 min after this intervention. Mean aortic pressure increased immediately after simulation of birth and then stabilized, whereas mean pulmonary artery pressure underwent a significant progressive decline. Left and right ventricular end-diastolic pressures and peak dp/dt increased after cord clamping and ventilation. Both contractile indices for both ventricles abruptly increased with cord clamping and ventilation and remained elevated for the duration of the experimental protocol.

\section{DISCUSSION}

Although others have concentrated only on the left ventricle ( 1 , 17), our study is the first to present chronologic postnatal data on both left and right ventricles in the newborn lamb. Previous determinations of the cardiac output in near term fetuses have revealed that flow through the left ventricle is approximately 170 $\mathrm{cc} / \mathrm{kg} / \mathrm{min}$, whereas that of the right ventricle is approximately $300 \mathrm{cc} / \mathrm{kg} / \mathrm{min}$ (12). Comparison of our data (Table 1) and that of others $(1,3,17)$ with these values suggests that the newborn left ventricle must more than double its output, whereas the right ventricle increases its flow by at least one-third at birth. This additional blood flow may be required to meet the increased tissue oxygen demands of the newborn which are reflected by a two- to three-fold increase in postnatal oxygen consumption (3). However, anatomic $(7,14)$, biochemical $(24)$, and hemodynamic investigations $(4,7,16,17,20,27)$ demonstrate that the newborn myocardium is immature and has a limited intrinsic ability to increase cardiac output. Thus, it is likely that some extracardiac mechanism enables the immature newborn heart to suddenly adapt to the increased demands of extrauterine life.

To assess one mechanism by which the immature newborn ventricles might achieve and maintain elevated cardic output after birth, we examined left and right ventricular inotropic state by determining pressure-velocity relationships during isovolumic systole. The indices which we calculated have been shown to be highly sensitive to alterations in inotropic state $(19,28,30)$. Nevertheless, theoretical objections have been raised to their use (22), and some investigators have shown that under certain circumstances these indices may be affected by acute changes in loading conditions $(22,33)$. In contrast, others have found these indices to be stable during acute changes in preload or afterload $(11,20,29,31)$. Thus, it was necessary for us to show that these indices reflected changes in ventricular contractility and in turn were unresponsive to alterations in preload and/or afterload in our experimental preparation and under the conditions of our protocol.

Therefore, we examined the effects of changing hemodynamics on contractile indices by acutely altering preload, afterload, and inotropic state in lambs of each age group (Fig. 1). These interventions demonstrated that, in our preparation and under the conditions of our protocol, $\mathrm{V}_{\max }$ and $\mathrm{V}_{\mathrm{CE} 10}$ were sensitive to alterations in inotropic state, but were not influenced by acute changes in preload or afterload, which exceeded in magnitude the maturational changes we encountered in our lambs. Independence of these indices from loading conditions was further supported by the sustained elevations in postnatal $V_{\max }$ and $V_{C E 10}$ of both ventricles, despite the fact that afterload of the left ventricle increased while that of the right ventricle decreased with maturation (Table I).

Rapid and continuing alterations in newborn ventricular morphology might also alter contractile indices. Despite postnatal 


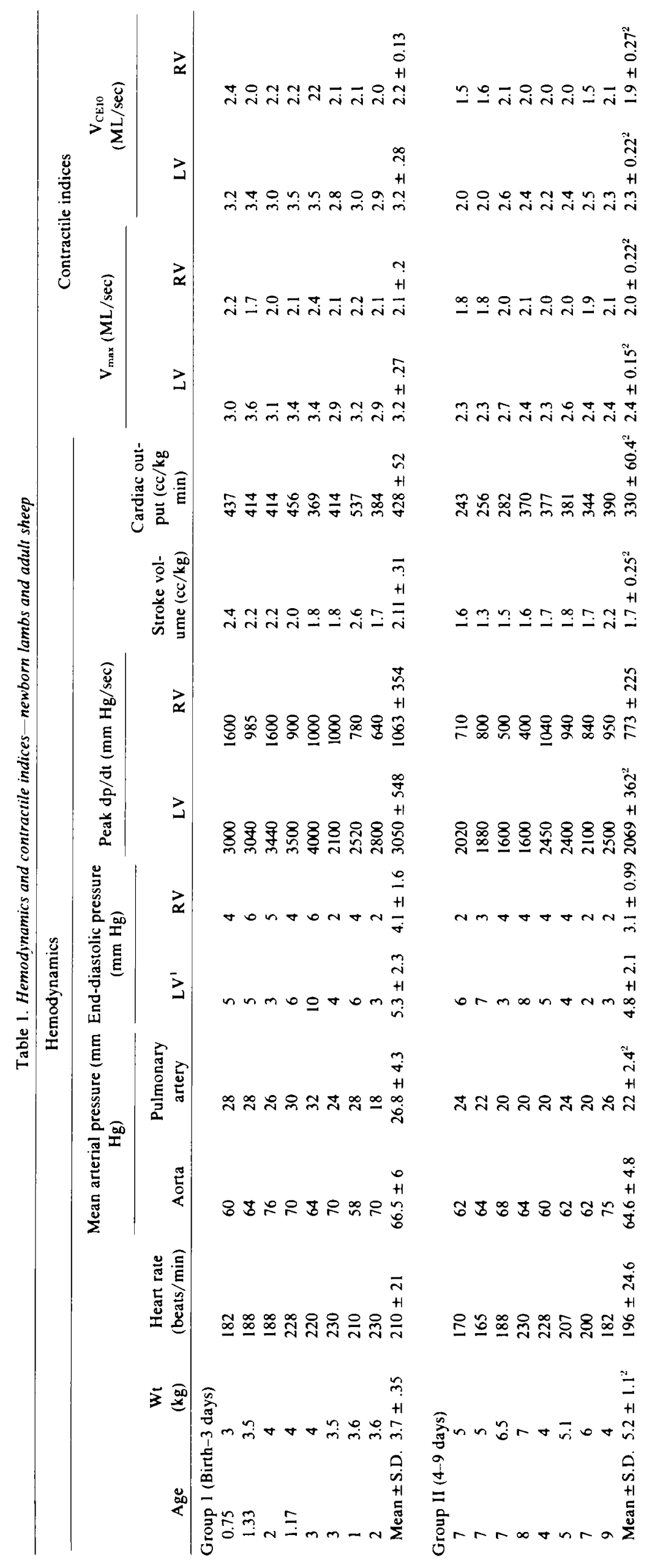


Group III (10-21 days)

\begin{tabular}{ll}
16 & 8 \\
10 & 9.3 \\
12 & 6 \\
15 & 5 \\
15 & 9 \\
10 & 5.5 \\
18 & 9.1 \\
15 & 5.9 \\
\hline
\end{tabular}

$\begin{array}{ll}120 & 74 \\ 214 & 80 \\ 193 & 68 \\ 200 & 70 \\ 174 & 68 \\ 207 & 85 \\ 222 & 60 \\ 162 & 71 \\ 187 \pm 33.5 & 72 \pm 7.7\end{array}$

$\begin{array}{lrr}22 & 4 & 3 \\ 26 & 10 & 6 \\ 28 & 7 & 4 \\ 20 & 6 & 4 \\ 18 & 4 & 5 \\ 27 & 2 & 3 \\ 17 & 5 & 2 \\ 12 & 3 & 2 \\ 21.3 \pm 5.6^{2} & 5.1+2.5 & 3.6 \pm 1.4\end{array}$

$\begin{array}{ll}1930 & 1060 \\ 2600 & 300 \\ 1400 & 800 \\ 2200 & 400 \\ 2100 & 400 \\ 1520 & 640 \\ 1800 & 450 \\ 1800 & 560 \\ 1919 \pm 384^{2} & 576 \pm 252^{2}\end{array}$

$\begin{array}{ll}1.8 & 2 \\ 1.1 & 235 \\ 1.4 & 277 \\ 1.3 & 248 \\ 1.4 & 251 \\ 1.8 & 380 \\ 1.2 & 263 \\ 2.3 & 365\end{array}$

$\begin{array}{ll}212 & 1.8 \\ 235 & 2.2 \\ 277 & 2.2 \\ 248 & 1.8 \\ 251 & 1.8 \\ 380 & 1.8 \\ 263 & 2.0 \\ 365 & 2.3\end{array}$

1.8
2.2
2.2
1.8
1.8
1.8
2.0
2.3
$2.0 \pm 0.2^{2}$

$\begin{array}{lll}1.6 & 1.8 & 1.5 \\ 2.1 & 2.1 & 2.0 \\ 1.6 & 2.2 & 1.7 \\ 1.6 & 1.7 & 1.6 \\ 1.5 & 1.6 & 1.4 \\ 1.5 & 1.8 & 1.5 \\ 1.7 & 1.8 & 1.6 \\ 1.6 & 2.0 & 1.5 \\ 1.7 \pm 0.19^{2} & 1.9 \pm 0.21^{2} & 1.6 \pm 1.9^{2}\end{array}$

Group IV (22-84 days)

$\begin{array}{ccc}29 & 9.1 & 168 \\ 40 & 13 & 182 \\ 22 & 18.1 & 168 \\ 84 & 17 & 120 \\ 27 & 12.7 & 200 \\ 30 & 18.1 & 158 \\ 32 & 14.1 & 188 \\ 46 & 11 & 232\end{array}$

$\begin{array}{ll}168 & 68 \\ 182 & 70 \\ 168 & 70 \\ 120 & 74 \\ 200 & 82 \\ 158 & 91 \\ 188 & 61 \\ 232 & 89 \\ 177 \pm 32.7^{2} & 75.6 \pm 10.6^{2}\end{array}$

$\begin{array}{lccl}20 & 8 & 8 & 1900 \\ 21 & 6 & 6 & 1500 \\ 20 & 6 & 4 & 2000 \\ 10 & 5 & 3 & 1400 \\ 28 & 3 & 2 & 2400 \\ 20 & 4 & 2 & 2100 \\ 23 & 8 & 2 & 2200 \\ 13 & 4 & 3 & 2600 \\ 19.4 \pm 5.6^{2} & 5.5 \pm 1.9 & 3.8 \pm 2.2 & 2013 \pm 412^{2}\end{array}$

$\begin{array}{ll}500 & 0.77 \\ 600 & 0.6 \\ 400 & 0.91 \\ 300 & 0.64 \\ 400 & 0.96 \\ 400 & 0.62 \\ 600 & 0.78 \\ 600 & 0.81 \\ 475+116^{2} & 0.76\end{array}$

0.77
0.6
0.91
0.64
0.96
0.62
0.78
0.81
$0.76 \pm 0.13$

$\begin{array}{rr}129 & 2.0 \\ 119 & 1.8 \\ 152 & 1.8 \\ 77 & 1.8 \\ 174 & 1.8 \\ 98 & 1.9 \\ 147 & 1.6 \\ 189 & 1.6 \\ 135.6 & \end{array}$

2.0
1.8
1.8
1.8
1.8
1.9
1.6
1.6
$1.78 \pm 0.13^{2}$

$\begin{array}{lll}1.5 & 2.0 & 1.6 \\ 1.4 & 1.9 & 1.5 \\ 1.5 & 1.7 & 1.4 \\ 1.6 & 1.5 & 1.4 \\ 1.5 & 1.8 & 1.5 \\ 1.4 & 1.8 & 1.0 \\ 1.5 & 1.8 & 1.4 \\ 1.5 & 1.9 & 1.4 \\ 1.79 \pm 0.15^{2} & 1.48 \pm 0.07^{2} & 1.3 \pm 0.3^{2}\end{array}$

Group V (adult sheep)

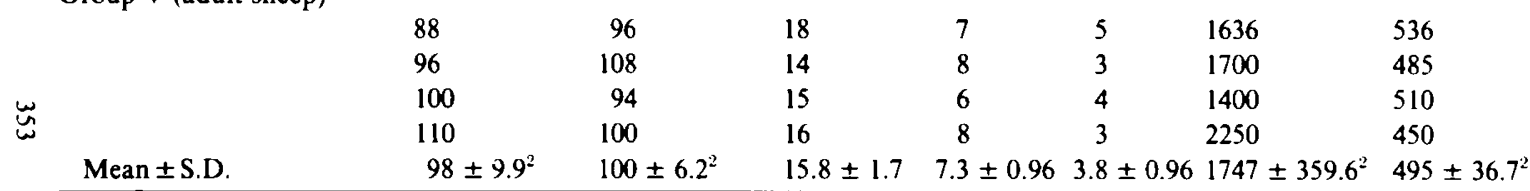

' $L V$, left ventricle: $R V$, right ventricle.

${ }^{2}$ Statistically significant ( $P \leq 0.05$ ) difference compared to mean values in $\mathrm{gp} I$ (birth to 3 days). 
Table 2. Hemodynamic data and contractile indices-fetal lambs

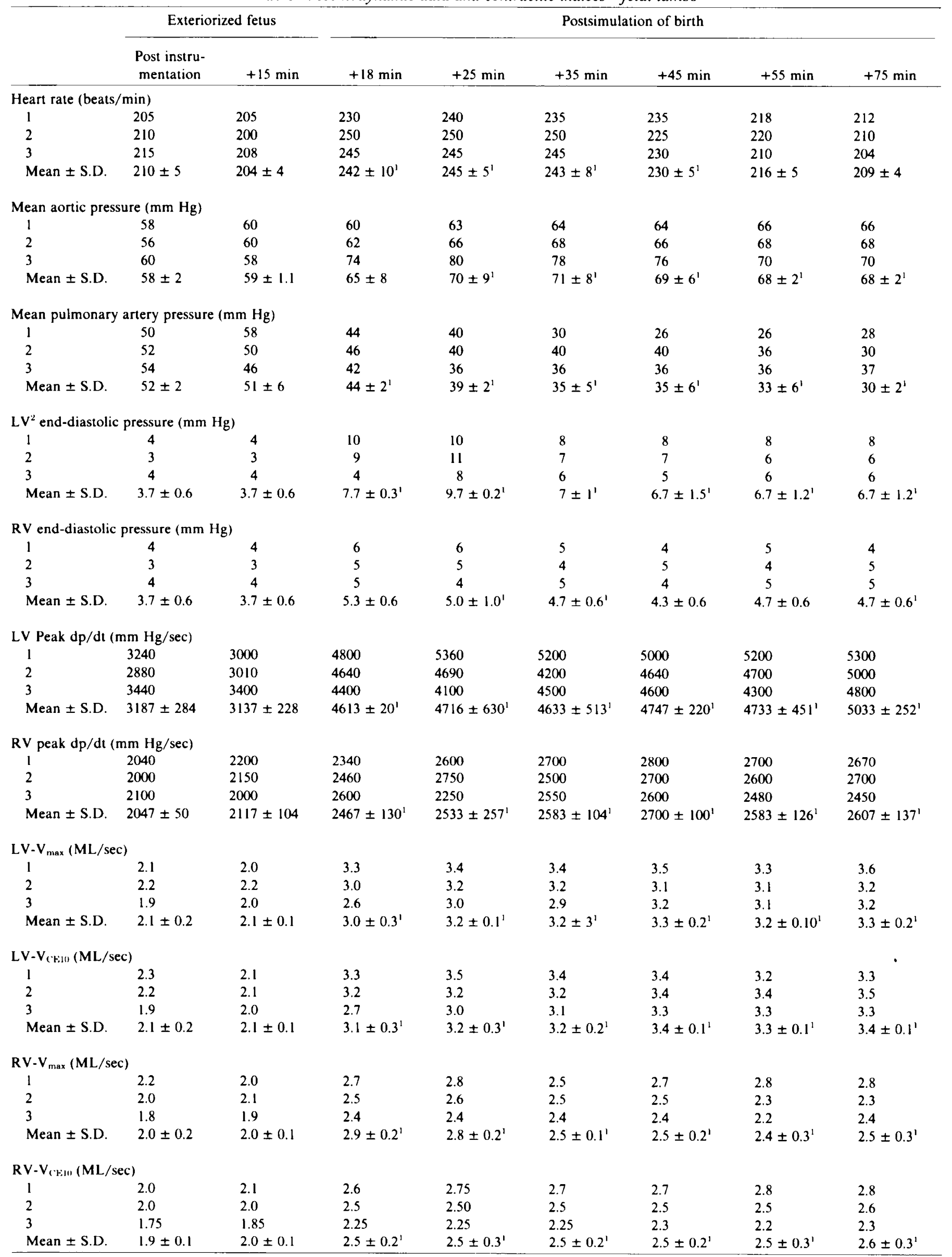

\footnotetext{
' Statistically significant difference ( $P \leq 0.05)$ compared to mean values of postinstrumented fetus.

' $L V$, left ventricle; $R V$, right ventricle.
} 
increases in ventricular mass, Lee et al. (19) have shown that left ventricular configuration is not altered in the neonatal period. Furthermore, contractile indices are expressed in representative units of muscle length and should thereby be independent of alterations in ventricular mass (20). Because data on neonatal ventricular compliance are conflicting $(8,15,18,21,26,30)$, it is difficult to predict how postnatal alterations in this parameter might affect myocardial function. However, previous studies in adult animals have clearly demonstrated that alterations in ventricular shape $(20)$, compliance $(2,35)$, or coefficient of elasticity (35) do not affect extrapolated $V_{\max }$, although they may influence individual measurements of instantaneous $\mathrm{V}_{\mathrm{CE}}$. The relatively small change in contractile indices between 10 and 84 days (Gps II to IV), despite continuing maturational changes in both cardiac structure and hemodynamics is an additional argument against dependency of isovolumic indices on any of these parameters in the newborn.

In addition, we considered the potential effects of anesthesia, thoracotomy, and instrumentation on neonatal ventricular function. In contrast to the marked depressant effect of barbiturates on myocardial function $(13,32)$, alpha chloralose has been shown to induce only minimal cardiovascular depression (32). Further, in the doses utilized, alpha chloralose does not alter oxygen consumption in the newborn lamb (3). Anesthesia, thoracotomy, and instrumentation might be expected to depress cardiovascular function to a greater degree in smaller (younger) animals. To the contrary, our data demonstrated that both cardiac output and contractile indices were elevated to the highest levels in the smallest lambs (Gp I) and to lesser degrees in older lambs (Gps II and III), as compared to adult sheep. Finally, our measurements of cardiac output in the newborn are comparable with those obtained by Klopfenstein and Rudolph (17), and Berman and Musselman (1) in recently instrumented awake newborn lambs.

The possibility of a causal relationship between heart rate and contractile indices is raised by the finding of more rapid heart rates in the youngest lambs $(\mathrm{Gp} \mathrm{I})$. However, comparison of heart rates and contractile indices (Fig. 2 ) demonstrates marked varia- bility in heart rates associated with only small differences in contractile state of older lambs (Gps II to IV). In contrast, elevations in contractile indices of far greater magnitude were observed whether comparing: (1) data from newborn lambs (Gp I) with those obtained from older lambs (Gps II to IV); or (2) data from exteriorized fetuses, postsimulated birth versus presimulated birth (Fig. 2; Tables 1 and 2).

Finally, acute surgical exteriorization of the fetus is associated with a decline in umbilical flow and related parameters of ventricular function (13). Nevertheless, contractile indices obtained after exteriorization of fetuses but before simulation of birth were stable and compared favorably with those obtained in older lambs (Gps II to IV), suggesting that acute exteriorization did not alter these measurements of contractile state in our fetuses to any great degree. Nevertheless, differing routes of administration of alpha chloralose to the fetus (maternal-fetal transfer) compared with the newborn (Gp IV), and the somewhat larger dosage on a per $\mathrm{kg}$ basis administered to the adult sheep versus the newborn, necessitate the caution that results obtained in the fetal lamb and adult sheep may not be comparable in every respect to the data obtained in newborn lambs.

We conclude that the age-related alterations in isovolumic contractile indices truly reflect an elevated ventricular inotropic state in the newborn lamb. We have demonstrated that these indices were influenced to only a minimal degree by postnatal changes in hemodynamics, ventricular structure, or techniques of our experimental protocol. Our data demonstrated that the elevated inotropic state of both left and right ventricles of the lamb is particularly marked in the first days of postnatal life (Gp I) and then diminishes toward adult levels (Gps II to IV) between 2 and 12 wk of postnatal existence. Data from exteriorized fetuses suggest that the increase in contractile state occurs suddenly, related to the events of birth.

The pattern of elevated inotropic state parallels the pattern of postnatal elevation in cardiac output. Although increases in cardiac output may be due in part to postnatal elevations in heart rate, our data suggest that a major factor in maintaining elevated

\section{RELATIONSHIP OF HEART RATE AND CONTRACTILE INDICES}

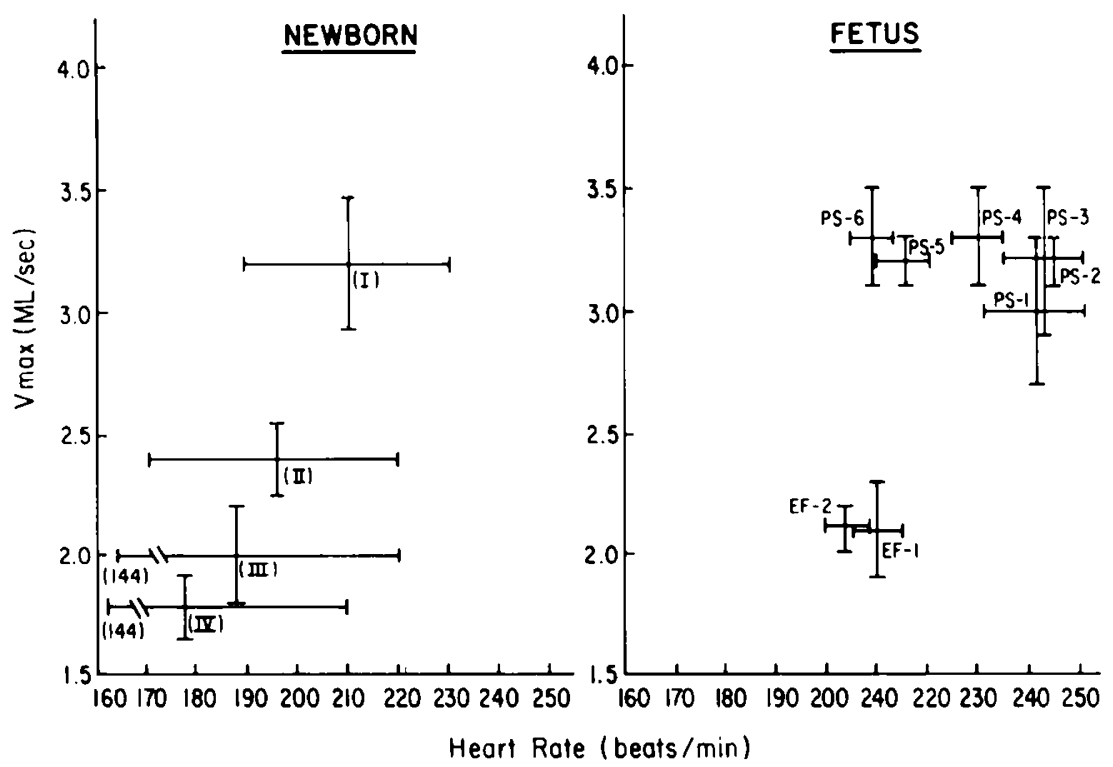

Fig. 2. Relationship of heart rate and contractile indices. Left, mean values ( \pm one $S . D$.) heart rate and $V_{\max }$ of each age group of newborn lambs (I to IV). Marked variability in heart rates, with only those of the oldest lambs (Gp IV) being significantly different from newborns (Gp I). In contrast, note that the contractile index $V_{\max }$ is significantly different from newborn (Gp I) values in all three older groups of lambs (Gps II to IV).

Right, panel relationship of heart rate and $\mathrm{V}_{\max }$ in exteriorized fetuses. Similarity of values for fetuses prior to simulation of birth (EF-1 and EF-2). After acute simulation of birth, note similar marked elevations in $V_{\max }$ despite variability in heart rates (PS 1-6). Although changes in heart rate may contribute to alterations in $V_{\max }$ and $V_{(E 10)}$, the primary cause of elevated contractile indices appears to be the events of the birth process. EF-1, 2 , exteriorized fetus immediately postinstrumentation, and 15 min after instrumentation; PS 1-6, Postsimulation of birth, 3, $10,20,30,40$, and 60 min. 
cardiac output is a birth-related increase in ventricular inotropic state. This postulation is supported by the finding of elevated stroke volume $/ \mathrm{kg}$ in our newborn lambs $(\mathrm{Gp} \mathrm{I}, 2.1 \mathrm{cc} / \mathrm{kg}) \mathrm{com}$ pared with similar values for both the instrumented fetus $[1 \mathrm{cc} / \mathrm{kg}$ - Heymann, et al. (12)], and the older lamb (Gp IV, $0.76 \mathrm{cc} / \mathrm{kg}$ ) (Table 1).

We speculate that the postnatal elevation in myocardial contractile state provides an immediate hemodynamic adaptation which assists the newborn heart to increase its output sufficiently to meet the initial demands of extrauterine life. Recent studies have shown that the birth process is associated with sudden elevations in circulating catecholamines $(5,9)$ and thyroid hormone (28). Both of these hormones are capable of inducing an elevation in myocardial contractile state (6) and might be expected to have a particularly marked effect on newborn myocardium, which is thought to be especially sensitive to catecholamines (9). Thus, one mechanism for elevated postnatal myocardial contractility and cardiac output, might be birth-induced elevations in circulating catecholamines or thyroid hormone.

\section{REFERENCES AND NOTES}

1. Berman, W.. and Musselman, J.: Myocardial performance in the newborn lamb. Am. J. Physiol., 237: H66 (1979).

2. Capone, R. J.. Mason, D. T., and Amsterdam. E. A.: The effect of mitral regurgitation and ventricular aneurysm on $V_{\max }$ calculated from pressurevelocity data during isovolumic systole. Circulation. 44 (Suppl. II): II (1971).

3. Cross, K. W.. Dawes, G. S., and Mott. J. C.: Anoxia, oxygen consumption and cardiac output in newborn lambs and adult sheep. J. Physiol. (Lond.), 146: 316 (1959).

4. Downing. S. E., Talner. N. D., and Gardner. T. H.: Ventricular function in the newborn lamb. Am. J. Physiol.. 280: 931 (1965).

5. Eliot, R. J., Lam, R., Artol, R., Hobel, C., and Fisher. F. A.: Norepinepherine, epinepherine, and dopamine levels at birth in the human cord and newborn samples. Clin. Res., 26: 198A (1978).

6. Epstein, S. E., Skelton, C. L., Levey, G. S.., and Entman, M.: Adenyl cyclase and myocardial contractility. Ann. Intern. Med., 72: 561 (1970).

7. Friedman, W. F.: The intrinsic physiologic properties of the developing heart, Chapter 2. In: W. F. Friedman, M. Lesch, E. H. Sonnenblick: Neonatal Heart Disease. pp. 21-49 (Grune \& Stratton. New York, 1973).

8. Friedman, W. F., McPherson, R. A., and Covell, J. W.: Active compliance in the fetal heart. Pediatr. Res., 9: 265 (1975).

9. Geis, W. P., Tatooles, C. J., Priola. D. V., and Friedman, W. F.: Factors influencing neurohumoral control of the heart in the newborn dog. Am. J. Physiol., 228: 1685 (1975)

10. Goldberg. S. J., Linde, L. M., Gaal. T. G., Momma, K., Takahashi, M., and Sarna, G.: Effects of barbiturates on pulmonary and systemic hemodynamics. Cardiovasc. Res.. 2: 136 (1968).

11. Grossman, W., Haynes, F., Paraskos, J. A., Salz, S., Dalen, J. E., and Dexter, L.: Alterations in preload and myocardial mechanics in the dog and in man. Circ. Res., 31: 83 (1972)

12. Heymann. M. A.. Creasy. R. K., and Rudolph. A. M.: Quantitation of blood flow pattern in the fetal lamb in utero. In: Proceedings of the Sir Joseph Barcroft Centenary Symposium: Fetal and Neonatal Physiology. pp. 129-135 (Cambridge University Press, Cambridge, 1973).

13. Heymann, M. A.. and Rudolph. A. M.: Effect of exteriorization of the sheep fetus on its cardiovascular function. Circ. Res., 21: 741 (1967).

14. Hopkins, S. F.. McCutcheon. E. P., and Wekstein. D. R.: Postnatal changes in rat ventricular function. Circ. Res., 32: 685 (1973).

15. Kane, R. L., McMahon, T. A., Wagner, R. L., and Abelmann. W. H.: Ventricular elastic modulus as a function of age in the Syrian golden hamster. Circ Res.. 38: 74 (1976).

16. Kirkpatrick, S. E., Pitlick, P. T., Naliboff, J., and Friedman, W. F.: FrankStarling relationship as an important determinant of fetal cardiac output. Am. J. Physiol., 231: 495 (1976).

17. Klopfenstein, H. S. and Rudolph, A. M.: Postnatal changes in the circulation and response to volume loading in sheep. Circ. Res., 42: 839 (1978).
18. Lee, J. C., and Downing. S. E.: Left ventricular distensibility in newborn piglets, adult swine, young kittens, and adult cats. Am. J. Physiol., 226: 1484 (1974).

19. Lee. J. C.. Taylor. J. F. N., and Downing. S. E.: A comparison of ventricular weights and geometry in newborn, young. and adult mammal. J. Appl. Physiol., 38: 147 (1975).

20. Mason, D. T., Spann, J. F., and Zelis, R.: Quantification of the contractile state of the intact human heart. Am. J. Cardiol., 26: 248 (1970).

21. Mirsky, I.: Assessment of passive elastic stiffness of cardiac muscle: mathematical concepts, physiologic, and clinical considerations, directions of future research. Prog. Cardiovasc. Dis., 18: 277 (1976).

22. Noble, M. I. M.: Problems concerning the application of concepts of muscle mechanics to the determination of the contractile state of the heart. Circulation. 45: 252 (1972).

23. Parmley. W. W., Chuck, L., and Yeatman, L.: Comparative evaluation of the specificity and sensitivity of isometric indices of contractility. Am. J. Physiol., 228: 506 (1975).

24. Riemenschneider, T. A., and Brenner. R. A.: Maturational changes in $\mathrm{Ca}++$ and $\mathrm{K}+$ activated myosin ATPase activity of the left and right ventricles. Am. J. Cardiol., 41: 298 (1978).

25. Riemenschneider. T. A., Burks, D. P., Jr., and Brenner, R. A.: Cardiac pump performance in lambs: maturational differences in left and right ventricular function. Circulation 56 (Suppl. 111): 111 (1977).

26. Romero, T., Covell. J.. and Friedman. W. F.: A comparison of pressure volume relations of the fetal, newborn, and adult heart. Am. J. Physiol.. 22: 1285 (1972).

27. Rudolph, A. M., and Heymann. M. A.: Fetal and neonatal circulation and respiration. Ann. Rev. Physiol., 36: 187 (1974)

28. Sack, J., Beaudry, M., LeLamater, P. V., Oh, W., and Fisher, D. A.: Umbilical cord cutting triggers hypertriodo-thyroninemia and nonshivering thermogenesis in the newborn lamb. Pediatr. Res., 10: 169 (1976).

29. Salel, A. F., Kamiyama, T., Peng, C. L., Mason, D. T.. Amsterdam, E. A., Massumi, R. A., and Zelis, R.: Quantification of right ventricular contractility by developed isovolumic pressure-velocity index. Clin. Res., 21: 447 (1973).

30. Templeton, G. H., Platt, M. R., Willerson. J. T., and Weisfeldt, M. L.: Influences of aging on left ventricular stiffness. Clin. Res., 23: 210A (1975).

31. Urschel, C. W., Henderson, A. H., and Sonnenblick, E. H.: Model dependency of ventricular force-volocity relations: importance of developed pressure. Fed. Proc., 29: 719 (1970)

32. Van Citters, R. L., Franklin. D. L., and Rushmer, R. F.: Left ventricular dynamics in dogs during anesthesia with alpha chloralose and sodium phenobarbital. Am. J. Cardiol., 13: 349 (1964).

33. Van de Bos, G. C., Elzinga, G., Westershof, N., and Noble, M. I. M.: Problems in the use of indices of myocardial contractility. Cardiovasc. Res., 7: 834 (1973).

34. Yeatman, L. A., Parmley, W. W., and Sonnenblick. E. H.: Effects of temperature on series elasticity and contractile element motion in heart muscle. Am. J. Physiol., 217: 1030 (1969).

35. Zelis, R., Amsterdam. E. A., and Mason, D. T.: Isometric $V_{\max }$ as an index of contractility independent of series elastic and fiber shortening. Implications concerning pressure-velocity data in myocardial fibrosis, valvular regurgitation. ventricular aneurysm, and ventricular septal defect. Circulation 44 (Suppl. 11): 11 (1971).

36. This research was presented in part at the 49th Annual Meeting of the American Academy of Pediatrics, Section of Cardiology, New York City. New York. November 5, 1978.

37. The authors gratefully acknowledge Dr. Forest H. Adams for his encouragement and helpful advice throughout the course of these studies. In addition we wish to thank Warren Dutton of Dixon, CA, for his selection and care of the animals used in this study, Hal Pullum and George Newton for their preparation of the illustrations, and Miriam Heikila for her excellent assistance in the preparation of this manuscript.

38. Requests for reprints should be addressed to: Thomas A. Riemenschneider, M.D. Chief. Section of Cardiovascular Pediatrics, UCDavis Medical Center 4301 X Street, Sacramento, California 95817 (USA).

39. This research was supported in part by a research program project grant HL14780 from the National Heart, Lung, and Blood Institute. National Institutes of Health. Bethesda, MD, and a research grant from the Golden Empire Chapter of the American Heart Association, Sacramento, CA.

40. Received for publication June 18, 1979.

41. Accepted for publication August 19, 1980. 